\title{
Garden Of Literacies: ICDT Contributing To The Construction Of New Realities For Digitally-Excluded Senior Citizens
}

\author{
Ivan Ferrer Maia \\ Universidade Estadual de Minas Gerais e Universidade Estadual de Campinas \\ José Armando Valente \\ Universidade Estadual de Campinas
}

\begin{abstract}
This paper shows how digitally-excluded senior citizens use information and communication technologies (ICT) for the construction of new literacies in the digital convergence culture. The concept of literacies is related to how ICT can be used to expand ways people express themselves through different communication channels. This study lasted three years and involved 16 adults aged between 60 to 78 years. The results showed that they were able to insert themselves into the digital culture with a more critical and creative attitude. Also, during this study it was possible to identify four types of literacies: automatic, functional, conscious and contextual.
\end{abstract}

Keywords: Literacies, Digital Literacy, Social Work, Social Web. 


\section{INTRODUCTION}

This study is associated with the investigations conducted at the Multidisciplinary Research-Action Healthy Community Laboratory - LIPACS by the Research Group "Culture, Society and Media" of the Institute of Arts of the State University of Campinas - UNICAMP - Campinas - São Paulo, Brazil. The Research Group and LIPACS joined efforts in order to conduct studies and surveys on the use of Information and Communication Digital Technologies (ICDT) applied to the teachinglearning process and on the impact of these technologies on society, in particular on the population regarded as excluded.

This paper will show the partial results of the activities involving digitally-excluded senior citizens. According to the Brazilian Census Bureau IBGE (2008), senior citizens in Brazil are the population with the least access to the Internet with rates as low as $11.2 \%$. Senior citizens who attended school for 4 years, on average recorded an even lower access rate: only $7.2 \%$ (IBGE, 2008). The higher the schooling level, the higher the Web access rate. In addition to the educational level, Internet access is also related to the monthly household per capita income.

The number of accesses made by senior citizens during the period of 2005 and 2008 increased from $7.3 \%$ to $11.2 \%$, respectively. Unfortunately, this result is not exclusively related to social inclusion policies, but rather to the death rate of senior citizens and the increase in the age of adults accessing the Internet.

These results confirm the need to provide poorly-educated, low-income senior citizens with proper conditions to come in contact with new technologies and with technology-based learning environments. This means that simply providing means to access new technologies is not enough. Instead, it is essential to offer support through learning agents duly prepared to work with senior citizens as well as to develop educational strategies which value their socio-cultural circumstances, life experience, dialogue, participation in the decision-making process and other aspects to properly raise the learners' awareness; in other words, consider the learner as a social-historical, consumer and political being. Therefore, the purpose of this paper is to show how digitallyexcluded senior citizens use technologies for the construction of new literacies in the digital convergence culture.

\section{THE LITERACIES}

Curiously, the terms literacy and literate were coined only after, in 1660, the Oxford English Dictionary registered the term with the negative connotation-illiteracy. The positive term literacy was only coined in the $19^{\text {th }}$ Century (Charnley \& Jones, 1979, p.8). In 1958, with the purpose of better understanding the statistics on illiteracy, UNESCO provided the following definitions:

\footnotetext{
"A person is literate who can with understanding both read and write a short simple statement on his everyday life. A person is illiterate who cannot with understanding both read and write a short simple statement on his everyday life." (UNESCO, 1958, p.93)
}

A literate person would be someone who mastered the normative grammar, recognized the graphic signs of a language and managed to code or decode it, both in writing and in reading. Based on such an approach and on Saussure's structuralism (1995) in Europe, and on Bloomfield (1983) in the United States, formal education started to value the skills of distinguishing syllables, words, 
morphemes, graphemes, numeric sequences, and the transformation of phonemes into graphemes and vice-versa. From such a perspective however, the concept of literacy would be confused with that of merely being able to read and write. The literate person would be solely and exclusively a person who could read and write, because such person would master codes, such as the alphabetic and numeric codes, taught primarily at school, as an individually acquired competence.

Researchers, based on sociology and anthropology, raised the discussion about the need to consider new approaches to literacy, based on a convergence of ideas which include the social reality. The views which value the learners' context became the focus of the debate, which encompassed literacy as a social practice that is manifested according to the context where the linguistic communication would take place by means of writing productions. Through the dissemination of such ideas in European, Anglo-Saxon and Latin countries, the scientific community has termed the social context approach of literacy in a number of different ways: cultural (Baker et al, 2002), ethnographic (Finnegan, 1988), pragmatic (Hill \& Parry, 1994), and ideological (Street, 1999).

In the first approach, the graphemes and phonemes are already predefined and, therefore, the literacy process is carried out through the relationship between the signifier and the signified. In the social aspect, on the other hand, neither the linguistic elements, nor their relationships are actually predetermined. The subject creates or reinvents the representation system based on a close relationship between the subject and his or her social and historical context.

Tfouni (1988), one of the pioneers in the study of literacy in Brazil, attempts to distinguish the concept of literacy from that which involves mere initial reading and writing instruction. In a text published at a later date, she wrote: "While the initial reading and writing instruction encompasses the acquisition of basic reading skills by an individual, or by a group of individuals, literacy is focused on the social and historical aspects involved in the acquisition of a system written by a society" (Tfouni, 2006, p. 20). The author advocates that the process of acquiring the alphabet is oriented to the individual, while literacy targets the society, duly supported by the social and historical context.

Kleiman, on the other hand, defines literacy as "the practices and events associated with the use, function and social impact of writing" (Kleiman, 2006, p. 181). According to this author, literacy includes the social practices of reading and writing and the events in which such practices are put into action, as well as their impacts on society. Soares (2003, p.72) defends the position that "literacy is what people do with their reading and writing skills in a particular context and the relationship established between such skills and knowledge and social practices, needs and values". The author goes on to suggest that literacy implies the performance of a set of social practices related to reading and writing in a specific social context.

In order to understand how literacy takes place in a social context, researchers started to adopt the concepts of "literacy event" and "literacy practice" as its building blocks in order to analyze the phenomenon. Heath (1982) regards a literacy event as "any occasion in which a piece of writing is integral to the nature of the participants' interactions and their interpretative processes" (Heath, 1982, p.93). The literacy event can be a sequence of actions and involve one or more people performing reading or writing activities. The concept of literacy practice is taken to a higher level of abstraction and refers both to the behavior and to the social and cultural conceptualizations which provide the context for reading and writing, that is to say, it is associated with the way a social 
group culturally uses the written language. Therefore, literacy practices reveal the concepts, values and beliefs typical of a culture. They encompass not only the "literacy event", such as empirical situations of which literacy is a part, but also socio-cultural aspects of such events and the ideological preconceptions which support them (Robert \& Street, 1998).

A third approach to the concept of literacy takes into consideration the social and cultural aspects, but also expands the term beyond the "letters". The term - literacies - tends to be used in its plural form, not only because it refers to the multiple genres of the verbal language but also because it contemplates a number of communication channels and non-verbal languages. Literacy events are being studied in several digital platforms by researchers who do not follow the traditional line of reasoning about literacy as solely focusing on the word and on individualized practices. They use the concept of literacy as situated in the social and cultural context of activities developed in multiple platforms or in different communication channels - both verbal and non-verbal. Among those, we could mention some approaches: Stald (2008) carries out studies on the role played by cell phones in the identity creation of young students; Stern (2008) relies on the construction of websites to promote young authors and develop their identities; Gee (2007) analyzes the role of video games in encouraging learning and literacy; Goodman (2003) uses the production of videos to bring about social changes for stakeholders; and Buckingham (2008a, 2008b) and Potter (2008) study the construction of literacy through communications media. These researchers use common elements in their ideas: the use of a new technology, the set of competences required to deal with such technology, and the ability to provide social meaning to the knowledge acquired through the support of technology.

Digital technologies have fostered the convergence of media onto a single platform which provides hybrid media services, enabling the support of a number of communication channels simultaneously. The use of such technologies and their convergent languages calls for additional competences (Valente, 2007, p. 13), which include empowering learners with hypermedia, the use of animations, static images, sounds, the manipulation of hyperlinks and active participation. In the participative approach, Jenkins (2006) uses the term "convergence culture" to argue that convergence should be understood as something which transcends the technological process and gathers several functions of the media within the same devices. Convergence represents a cultural shift in which users do not respond passively but rather take on active roles in their search for new information and the establishment of connections among diffuse media contents (Jenkins, 2006, p.3).

In the convergence culture scenario, it may be asserted that literacies encompass social practices which rely on semiotic elements in such a manner that they interact with, complement, and transform one another due to the hybrid nature of digital technologies. A subject who reaches the level of literacies manages to grasp the strategies typically used by communication channels or ICDT, develops meaning based on them, works on the structure of the signifiers, and assists in the sensitive and cognitive transformations of the subjects themselves. And, based on such processes, the subject is able to assign social meanings to such a degree that the context may be transformed and new realities may be created in the world (Freire, 1980). Through the intellect and the senses, the subject perceives the reality of the context which shapes his/her own identity. According to Maturana, reality is the domain of things, and, in this sense, whatever can be distinguished is real (Maturana, 2001, p.156). By becoming aware of the reality, a subject can understand his/her context and how he/she is entangled in the complex fabric of relationships with the world. 
The power of transformation is directly related to raising the subject's awareness. According to Freire (1980), awareness is a reflective attitude of the subject's own condition and the condition of his/her social practices in the world. Freire believes that the subject may reach three levels of awareness: a primitive level, in the sense of responding automatically without being aware of the situation; the awareness of the external actions when the subject starts perceiving the social context; and the self-conscious level, when the subject clearly associates the social and historical context with his/her own current reality. Literacy practices that manage to reach the latter level of awareness will bring about the most significant transformations that can then cause an impact on the cognitive and perceptive realities and on the social and cultural context of the subject.

The purpose of this research paper thus is to understand how senior citizens are empowered with technologies in order to build new literacies and, with that, become aware of their capacity to function in the context where they live and build new realities.

\section{METHODOLOGICAL ASPECTS}

This study used Morin's method (2004) of integral and systematic action-research. This method presents the theory, techniques, procedures and participation, typically taking place in actionresearch as a systemic approach. In this sense, the interaction between the players and the researchers is analyzed in different modes and at varying levels, with the purpose of fostering a more democratic educational and social practice in the areas where the action-research is being conducted. This method provides the individual involved in the action with the possibility of intervening so as to promote changes in his/her life or in the community where he/she lives (Morin, 2004, p.91).

The field study lasted three years and consisted of weekly meetings of one-hour duration each. The meetings were held in the computer labs at the Integrated Schools Paiva de Vilhena University of Minas Gerais, located in the same neighborhood or close to the learners' homes, in the city of Campanha, in the south of Minas Gerais State, Brazil.

The study included 16 senior citizens, among whom 14 were women and 2, men. Their schooling ranged from 3 to 7 years of Basic Education, and all of them were regarded as digitally excluded. Practical activities were used including websites of interest to the group, emails, websites accessing audiovisual files and social network platforms. The actions were based on social and historical concepts and were supported by the strategy of dialog with the learners. The following information was provided by the learners: their personal backgrounds, lifestyles, their occupations, their hobbies, and their likes and dislikes. The teaching-learning-motivation-satisfaction relationship was sustained through dialog.

The tools used for data collection were the following: photography, videos, interview forms, group activities, assessment of face-to-face and remote activities using, in particular, Web 2.0 tools (Orkut, Vila na Rede[1]), as well as observations in loco, which were recorded through field logs. The data is still being analyzed and will be analysed using $\mathrm{CHIC}$ software (" $\mathrm{CHIC}$ " being the abbreviation of the French translation of Hierarchical Implicative and Coercitive Classification) whose purpose is to generate similarity graphs. CHIC software relies on a multidimensional statistical method used in qualitative studies of association rules matching different types of variables and displaying the results graphically.

Some examples of how senior citizens were empowered with ICDT being used for literacy construction are shown below. 


\section{MY GARDEN: LITERACY PRACTICES APPLIED TO SENIOR CITIZENS}

For an audience which was contemporary with the telegraph, tube TV sets and with little formal education, the challenge of overcoming the constraints acquired throughout their lives and of delving into the world of Wikis, Blogs, Orkut and YouTube was enormous. Setting up a favorable learning environment with the support of colleagues and the assistance of mediators made it easier for them to overcome these barriers and to start building the new concepts required to deal the emerging convergence culture, such as interaction, interactivity, hypertextuality and multimediality. To that end, it was crucial for the mediators to talk with the learners so as to get to know who they were, where they came from and what they did and are doing in their lives. The individuals were subjects with striking memories and experiences, situated in specific social and cultural contexts which, once understood, became the required leverage for the qualitative leap into literacy to occur.

Literacy practices were performed by relying on the broader concepts of "literacies" which considers both the social aspect and language variations (verbal and non-verbal). At first, the learners managed to master the basic PC operations: switch it on and off, handle the mouse and the keyboard, use the word processor and search websites - to name a few. In order to achieve these results, three main types of activities were used: digital games, typing of texts and access to vintage songs.

The literacy level was basic and learners would respond automatically or at the mediators' request. The awareness gain was primitive, varying from amazement to mystification. The level of interaction was also restricted and they were not interested in establishing any relationship with their peers but rather were concerned with their own performance and attainment. For that reason, the first contacts with the new technologies were particularly oriented towards activities which would provide the grounds for new users to break away from their sense of fear and push them towards another reality, that of the universe of digital technologies from which they were excluded.

Although the activities at this stage did not involve complex operations, social and cultural elements that were meaningful to them and which were closely related to their context were used. This is shown in Figure 1, where some senior citizens are developing individual activities. Each one is doing activities on particular websites or using specific software programs, according to their own needs or interests. These practices were associated with typing exercises, educational games and access to old songs.

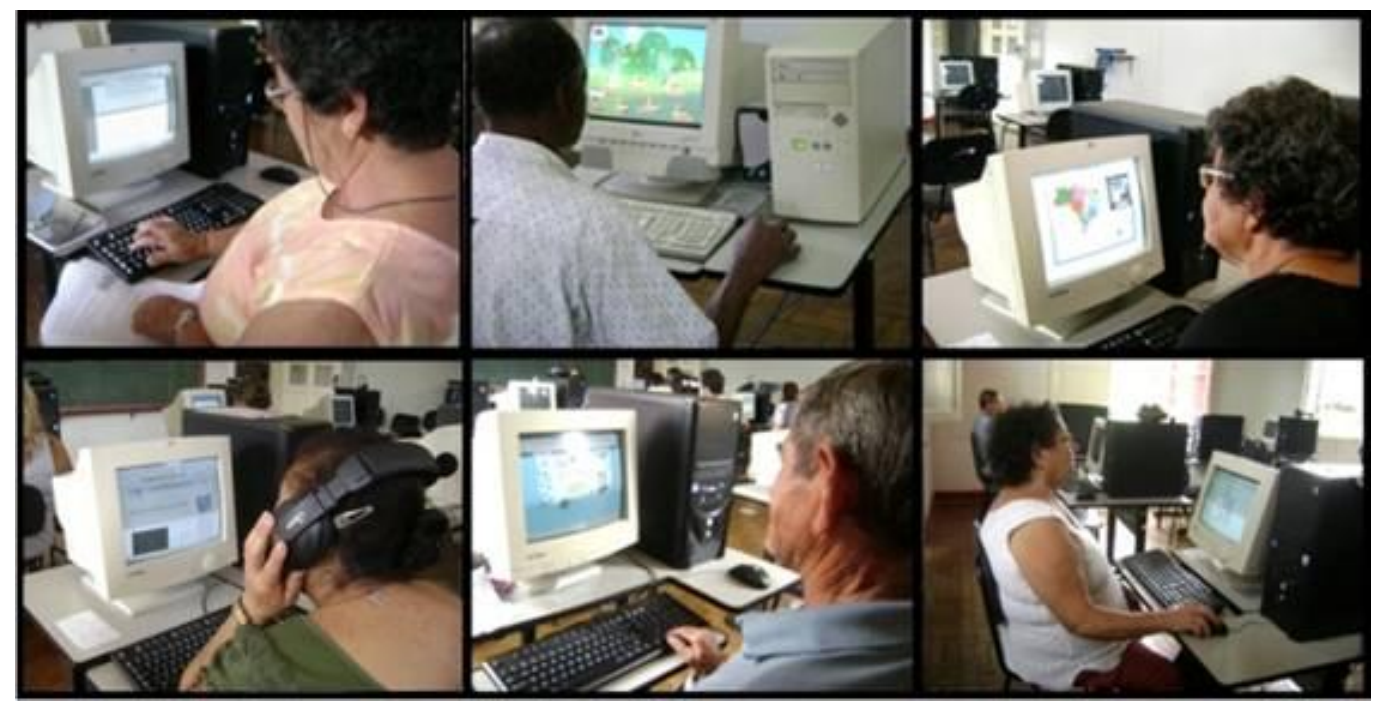

Figure 1. Literacy practices using Information Technology. 
Over time the learners started doing activities involving emails, website search and social networks (Orkut). At this point they responded somewhat more spontaneously and reflectively. It was noticeable that they started to shift from the previous reality towards an understanding of a network-based context. Despite that, the learners did not relate such learning to their own immediate context. The level of interaction was regarded as moderate because the relationships they established with other colleagues were limited to simple replies to emails or Orkut messages. They did not interact on their own and did not establish relevant reflexive relationships with their own contexts.

With the support of the mediators, the activities were further developed towards ever more complex operations, thus building multiple competencies (Valente, 2008). Those accomplishments enabled learners to reach more significant results such as accessing information on a bank strike and communicating that to a spouse, her husband; collecting information on a music festival (Festival da Canção) and registering for the contest; searching for a music score on the web; getting in contact with TV stations; finding the text of a new law published by the Brazilian Environment and Renewable Resources Institute (Instituto Brasileiro do Meio Ambiente e dos Recursos Naturais Renováveis - IBAMA); correctly filling out invoices to be used at the learner's own woodworking business; resuming their studies by participating in the Adult Literacy program and accessing the Internet for educational research; playing the role of learning agents for family members by helping a spouse or children; and even meeting a boyfriend via the Web and maintaining daily contact through email and MSN. Thus the learners managed to develop literacy practices, provide a social use for the digital technologies and understand a reality which could, through the web, offer them access to information, exchanging of messages remotely and helping them learn in various topics areas.

It is worth mentioning that one of the activities performed with the learners, namely, "My Garden", which contributed to the process of empowering learners with the technologies and to develop the literacy practices (Heath, 1982), encompassed both social aspects and the use of different languages or communication channels. The purpose of the "My Garden" activity was to awaken the learners' awareness of their reality and to encourage contextual transformation based on Freire's transformation principle (1980). For this purpose, a topic of interest to the group was selected: gardening.

The activity started with a presentation on gardening delivered by a learner. This presentation was an integral part of the information technology activities planned for this learner. In addition, the learner was in the process of acquiring reading and writing skills and did not feel that he fit in the group. However, he became the leader the moment he made the presentation of his own professional activities as a gardener at an Institute of Higher Education.

He gave a presentation to the entire group describing how he took care of the plants. He presented a number of species, the special care each plant required, all in loco, in the garden of the Institute where he works, in order to highlight what could be observed by the learners. With his self-esteem boosted, the gardener/learner fascinated the entire group with his gardening topic.

Mediators took advantage of the moment to encourage debate among the learners so that, based on what was being observed, discussions were developed on how gardens related to each person's own life. The mediators asked who had a garden or a kitchen garden to take care of; if their own lives were a garden, what were the similarities and differences between a garden and life? In addition to the family, what are the other nice flowers (as metaphors for good events) which 
bloomed in their own lives (garden)? Why were they good? Which bad flowers grew in the garden and why did they grow at all? In this way, the mediators attempted to take the discussions to a higher level so as to include historical, political, social and cultural viewpoints.

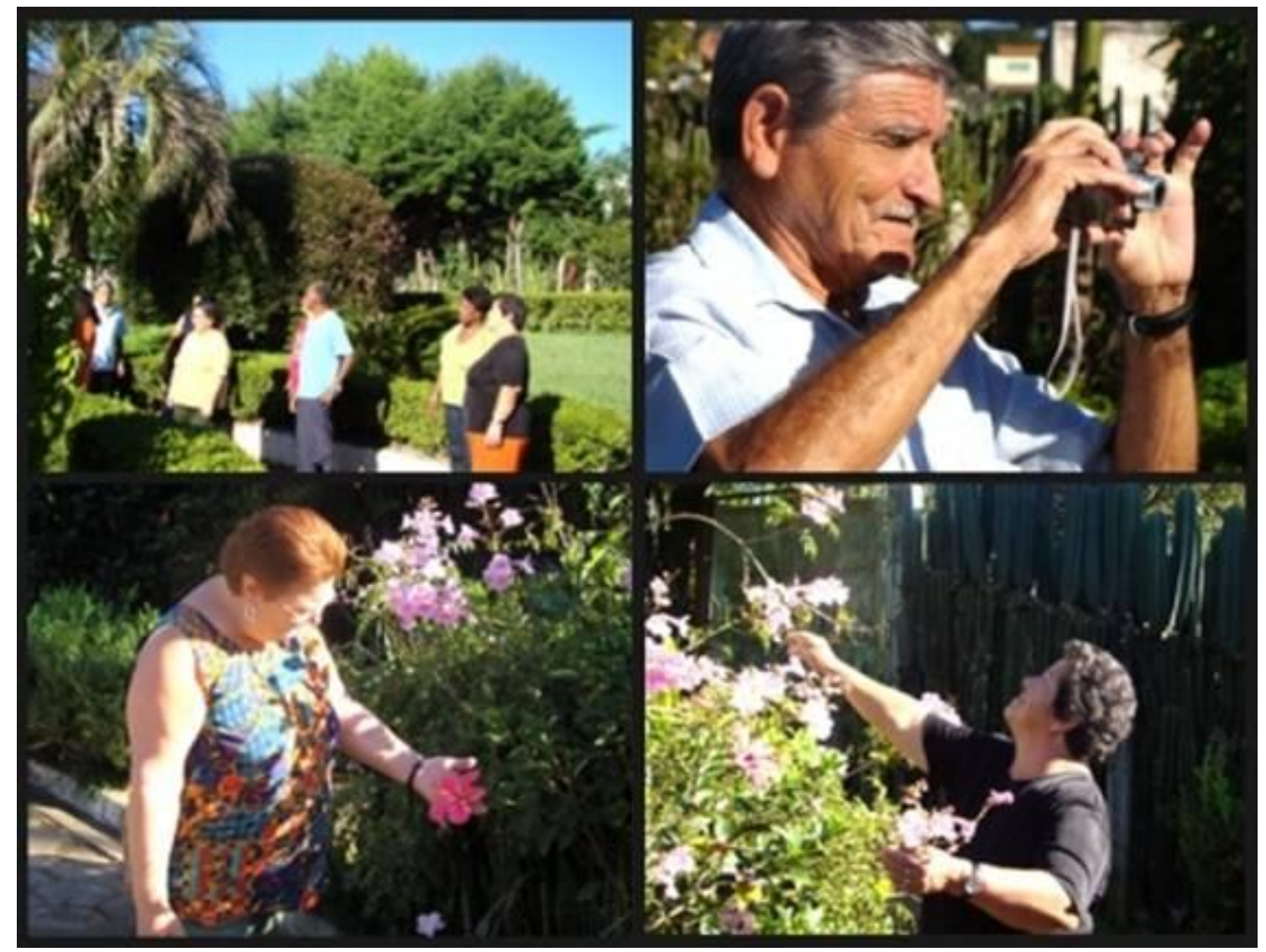

Figure 2. Literacy activity in the garden.

Figure 2 shows learners in the garden of the Institute doing a group activity; a learner taking pictures of flowers and colleagues; and learners observing flower details. These images depict the initial moments when a background context was being established for the activity referred to as "My Garden", which contributed to the collective discussions described above. Such discussions helped encourage the collective discussion of individual experiences, sharing of similar experiences and challenging the reasons that led to those facts in their own lives/gardens. Based on those discussions, reflections as to how some situations could be changed were encouraged.

Digital technologies also contributed to the exercise. In addition, the learners visited websites and poetry blogs which helped them relate their lives to the garden. They also watched videos of the impressionist painter Monet on YouTube. The artist Monet was chosen by the learners as a reference in order to build the relationship between life, work and the garden. After reading the texts, each learner used a word processor to write a message associating his/her life with the garden.

With regards to recording of images, especially with the purpose of helping them to manipulate these, learners took pictures of the garden they visited and of meaningful objects found in their own home, or objects which are now or used to be part of their lives in order to represent the garden itself. Messages with the images were inserted into the slides in Power Point software program and were emailed to friends and relatives. 
Two Web 2.0 tools contributed to this activity on gardening, namely Orkut and Vila na Rede. These platforms became the garden bed where "new flowers" were planted. Several learners used those platforms to add activities from their homes, as part of their daily routine, such as handicrafts, or even cookery products - oil painting on canvas, fabric paintings, crochet, kitchen towels, bath towels, tablecloths, diapers, pastries, etc.

Learners also developed content and added this to their websites, for example, videos on how to crochet and to make bags from recycled materials. The work received a lot of feedback and users from other cities were interested in buying these products. Another example was a family recipe which was posted: for a banana pastry. On the website, a user exchanged information with a learner on how to make good use of banana peels. Another learner enjoyed the banana pastry so much that she prepared the recipe at home and took the pastries for her colleagues to try. At that stage, the learners were already able to rely on the technologies and provide social meaning and use to them in an everyday context. In addition, they worked as participants in the convergence culture, according to Jenkins' (2006) proposal of an active subject who takes on the leading role in the scenario of digital technologies.

Figure 3 presents some examples of those events. On the Vila na Rede website (to the left), there are videos showing a learner teaching how to make accessories (bags, belts) through crochet and recycled materials, in this case, aluminum can lids. To the right, a learner posts her handiwork production on Orkut.

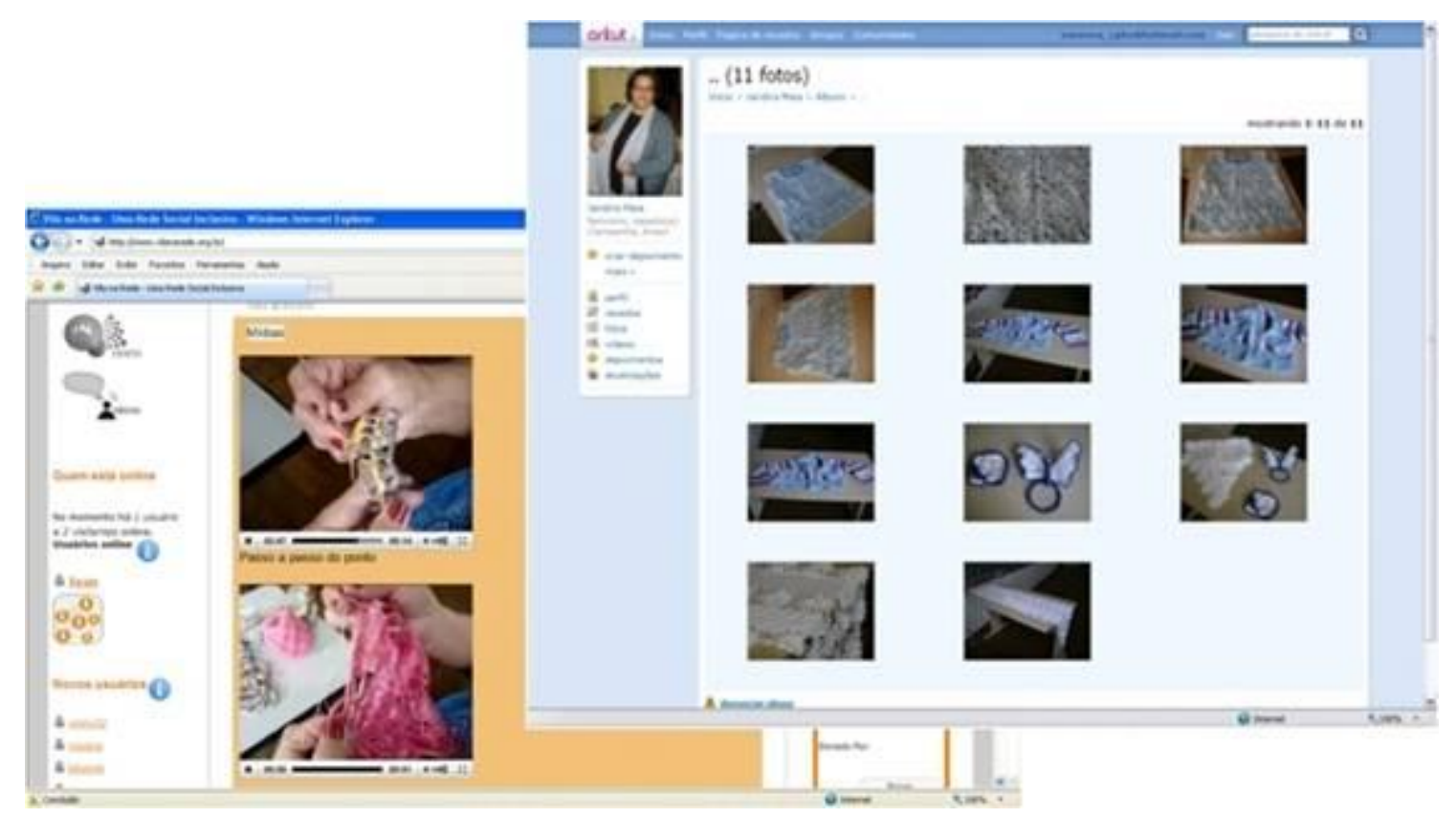

Figure 3. Many educational videos on the Vila na Rede website and photos of handicraft were added to the Orkut social network.

The contents developed and the products posted were chosen by the learners themselves. After the activities were further developed using educational strategies connected to their own lives, the qualitative leap in their learning was clear. Some learners managed to display reflections on the importance of the activity to their own lives.

Those who managed to reach this level, understood the causal and circumstantial events and related them to their own reality or context to create new realities. Such characteristics became clearer when the learners became aware that the digital tools could help them express themselves by adding their own handicraft production or by debating their ideas. We could see increased 
awareness of the social use of the ICDT to the degree of even transforming the context, that is, the learners' lives. These changes in reality were noticed both in the intellectual aspect and in relation to ICDT, as well as in terms of practices in specific social contexts. Through the use of digital media, they also had more advanced interactions, promoting more significant dialog between peers.

\section{TYPES OF LITERACIES}

In the beginning, since learners were not familiar with information technology, they had to master the basic literacies and learn the building blocks of IT, as well as to learn how to perform basic hardware and software operations. Only then did they manage to give their learning a functional application, such as accessing information or reading an email. The most significant gain in awareness was when they noticed that they could use technology for social purposes. They then enhanced their interactions and expanded their social network.

Proposals to handle more complex operations were gradually introduced and the pace was reduced so that learners would not feel pressured, develop a sense of failure and eventually quit. Based on these results, four types of literacies could be described:

Automatic Literacies - The user functions in the input and output mode, that is to say, the stimulus-response mode, without any grasping of awareness and individual learning. For example: turn the computer on and off, handle the mouse, use the keyboard.

Functional literacies - The user manages to make practical use of ICDT. There is some awareness of digital technology functions and they begin to be used, but without significant or complex transformation at the cognitive, perceptive or contextual levels. For example: information is accessed on the web but it is not used meaningfully.

Conscious Literacies - The user encourages reflections, cognitive and perceptive transformations. There is full awareness of the use of ICDT in the own lives. In addition to being able to use ICDT for functional purposes, learning or skill development is perceived. For example: uses a website to pay bills or to buy products.

Contextual literacies - In addition to raising their awareness, encouraging cognitive and perceptive transformations, the users manage to bring about social and cultural changes in the context. Technology is adopted as part of their own culture. It is actively incorporated into their daily lives. For example: posting contents to websites or social networks, interacting through web platforms, etc.

In all these types of literacies, varying degrees of intellectual transformations were perceived, including transformations in the context itself. However, these transformations took place gradually as new competences were learned and the skills to foster further awareness were mastered. The more knowledge was acquired, the more intense were the literacy practices and more meaningful were the transformations. The nature of the transformations ranged from intellectual, to perceptual and even contextual aspects. Learners built new realities, started to adopt an active role in the social network and to contribute not only with content but also to routinely rely on ICDT from a cultural standpoint. In these new realities, learners used ICDT mainly for the following purposes: to search for information, to foster communication, for entertainment, as a learning tool, to market products, to generate content, to organize their finances and to preserve family memories. These 
results indicate that they managed to code and decode meanings and to attribute a social use to them, generating knowledge applicable to their own lives.

\section{FINAL CONSIDERATIONS}

The paper described literacy practices related to the means by which digitally-excluded senior citizens overcame social and historical constraints, gained more awareness of and mastered ICDT so as to become active and creative members of the convergence culture and build new realities.

For the development of the learners' activities the learners' contextual reality, the relationship of the existing power structure, aesthetic productions, technical mediations, socially established meanings, and the political and economic contexts in which the languages and technologies were inserted were taken into consideration.

Literacies brought about new representations, awakened the conscience and expanded the communications systems as a means of interaction with the world. Those who reached the literacy level managed to build new realities because they were able to understand and apply digital technology strategies, assign meanings based on such technologies, act upon the structure of the signifiers and assist in the sensitive and cognitive transformations so as to boost awareness, apply it to cultural aspects and promote changes in their social environment and realities.

\section{ACKNOWLEDGEMENTS}

The success of this project was only possible thanks to the support provided by Minas Gerais Research Foundation - FAPEMIG, São Paulo Research Foundation - FAPESP, National Counsel of Technological and Scientific Development - CNPQ, Integrated Schools Paiva de Vilhena associated with the University of Minas Gerais (UEMG), by the UEMG research and extension program, by the Multidisciplinary Research-Action Healthy Community Laboratory - UNICAMP and all collaborators, researchers and, in particular, the learners involved in the project.

\section{BIBLIOGRAPHY}

Baker, D. A., Street, B., \& Tomlin, A. (2002). Math as social: Understanding relationships between home and school Numeracy Practices submitted to FLM.

Buckingham, D. (2008a). Defining digital literacy. What do young people need to know about digital media? In: C. Lankshear, \& M. Knobel (Eds.). Digital literacy: concepts, policies and practices. New York, USA: Peter Lang.

Buckingham, D. (2008b). Media education: literacy, learning and contemporary culture. Cambridge, UK: Polity.

Charnley, A. H., \& Jones, H. A. (1979). The concept of success in adult literacy. London: ALBSY.

Finnegan, R. (1988). Literacy and Orality: studies in the technology of communication. New York: Basil Blackwell.

Freire, P. (1980). Conscientização. Teoria e prática da libertação: uma introdução ao pensamento de Paulo Freire. São Paulo: Moraes. 
Gee, J. P. (2007). What video games have to teach us about learning and literacy. New York: Palgrave MacMillian.

Goodman, S. (2003). Teaching youth media: a critical guide to literacy, video production, and social change. New York: Teachers College Press.

Heath, S. B. (1982). Protean shapes in literacy events: ever-shifting oral and literate traditions. In D. Tannen (ed.). Spoken and written language: exploring orality and literacy. Norwood, NJ: Ablex.

Hill, C., \& Parry, K. (Eds.). (1994). From testing to assessment: English as an international language. London: Longman.

IBGE. (2008). Acesso à internet e posse de telefone móvel celular para uso pessoal. Brasilia, DF: IBGE. Retrieved 14/08/2009. URL: http:// www.ibge.gov.br/home/default.php

Jenkins, H. (2006). Convergence culture: where old and new media collide. New York, London: New York University Press.

Kleiman, A. B. (2006). Ação e mudança na sala de aula: uma pesquisa sobre letramento e interação. In R. Rojo (ed.). Alfabetização e letramento. São Paulo: Mercado de Letras.

Maturana, H. (2001). A ontologia da realidade. Belo Horizonte: UFMG.

Morin, A. (2004). Pesquisa-ação integral e sistêmica: uma antropopedagogia renovada. Rio de Janeiro: DP\&A.

Potter, W. J. (2008). Media literacy. Thousand Oaks, California: Sage.

Robert, C., \& Street, B. (1997). Spoken and written language. In F. Coulmas (ed.). The Handbook of Sociolinguistics. London: Blackwell.

Soares, M. (2003). Letramento: um tema em três gêneros. Belo Horizonte: Autêntica.

Stald, G. (2008). Producing site, exploring identities: youth online authorship. In D. Buckingham (ed.). Youth, identity, and digital media. Cambridge, Massachusetts: The MIT Press.

Stern, S. (2008). Producing site, exploring identities: youth online authorship. In D. Buckingham (ed.). Youth, identity, and digital media. Cambridge, Massachusetts: The MIT Press.

Street, B. (1999). Literacy in theory and practice. Cambridge: Cambridge University Press.

Tfouni, L. V. (1988). Adultos não alfabetizados: o avesso do avesso. São Paulo; Campinas: Fontes.

Tfouni, L. V. (2006). Letramento e alfabetização. São Paulo: Cortez.

UNESCO (1958). Recommendation concerning the International Standardization of Educational Statistics. Paris: UNESCO. Retrieved 09/01/2009. URL: http://unesdoc.unesco.org/images/0011/001145/114584e.pdf\#page=88

Valente, J. A. (2007). As tecnologias digitais e os diferentes letramentos. Pátio Revista Pedagógica, Porto Alegre, ano. XI, n. 44, p. 12-15, nov. 2007. 
[1] Vila na Rede is an inclusive social network developed as part of the Project e-Cidadania (e-Citizenship) at the State University of Campinas, São Paulo, where products, services, events and ideas can be shared in order to benefit the community as a whole. URL: http://www.vilanarede.org.br 